\title{
Study of induction of labour with vaginal misoprostol in a tertiary hospital in a rural area of Telangana, India
}

\author{
Kavitha Reddy Kothapally*, Vasantha Kavati, Vydehi Bongu
}

Department of Obstetrics \& Gynaecology, Bhaskar Medical College \& General Hospital, Yenkepally, Moinabad, Telangana, India

Received: 20 February 2015

Revised: 28 February 2015

Accepted: 01 March 2015

\section{*Correspondence:}

Dr. Kavitha Reddy Kothapally,

E-mail: kavitha.nkothapally@gmail.com

Copyright: ( $)$ the author(s), publisher and licensee Medip Academy. This is an open-access article distributed under the terms of the Creative Commons Attribution Non-Commercial License, which permits unrestricted non-commercial use, distribution, and reproduction in any medium, provided the original work is properly cited.

\begin{abstract}
Background: The present study aims at the analysis of obstetric outcome of induction of labour with $25 \mu \mathrm{g}$ of vaginal misoprostol in pregnancies beyond 36 weeks of gestation with unfavourable cervices.

Methods: The present observational study was conducted at Bhaskar medical college \& general Hospital, Yenkepally, Telangana from march 2014 to October 2014. 116 pregnant women were enrolled into the study based on appropriate indication for labour induction with $25 \mu \mathrm{g}$ of vaginal misoprostol inserted fourth hourly till maximum of four doses or till the desired response was obtained.

Results: Common indications for induction were postdatism (50.86\%), pregnancy induced hypertension (PIH$19.82 \%$ ), premature rupture of membranes (PROM-14.66\%) \& oligohydramnios (14.66\%). Poor Bishop score of less than 4 was seen in $66.38 \%$ of cases. Normal vaginal delivery occurred in 60 cases $(51.72 \%)$ against Lower Segment Cesarean Section (LSCS) for various reasons in 56 cases (48.28\%). Successful induction, measured as onset of active labour (3 contractions in $10 \mathrm{~min}$ with duration of $40 \mathrm{sec}$ of each contraction) or cervical dilatation of $3 \mathrm{~cm}$ or successful vaginal delivery, was seen in 107 (92.24\%) cases. Failed induction measured as no cervical changes or no onset of labour pains even after 4 doses of vaginal misoprostol was seen in 9 cases (7.76\%). Out of 60 successful vaginal deliveries 2 doses of misoprostol was required in 27 cases (45\%) \& 1 dose was required in 29 cases (48.33\%). Induction delivery interval of 7-12 hours was seen in 26 cases (43.33\%). Maternal complications were seen in 27 cases $(23.28 \%)$, common ones being postpartum haemorrhage (PPH) \& PROM. No case of uterine hyperstimulation or rupture was seen. In 113 cases $(97.41 \%), 5$ min APGAR score was more than 7 . Neonatal Intensive Care Unit (NICU) admissions in the newborn was 4 (3.45\%).

Conclusions: Hence labour induction with 25 microgms of vaginal misoprostol in pregnancies with unfavourable cervices improves Bishop's score, reduces induction delivery interval, reduces caesarean section rates $\&$ does not affect fetal outcome.
\end{abstract}

Keywords: Labour induction, Vaginal misoprostol, Bishop score

\section{INTRODUCTION}

Induction of labour is the artificial initiation of labour before its spontaneous onset for the delivery of fetoplacental unit using mechanical or pharmacologic methods. ${ }^{1}$ Labour induction is a common intervention in obstetrics, required in upto $30 \%$ of pregnancies. ${ }^{2,3}$ Since success of labour induction depends on cervical status at the time of induction, poor Bishop's score $(<4)$ has high rate of failure of induction. ${ }^{4}$ Favorability of the cervix for success of labor induction can be achieved by the use of prostaglandins. New synthetic $\mathrm{PGE}_{1}$ analogue' misoprostol', licensed primarily for the prevention \& 
treatment of NSAID induced ulcers of gastrointestinal tract, is a promising agent for labour induction. ${ }^{5}$ It is conveniently administered through oral, sublingual, buccal, vaginal \& rectal routes. ${ }^{5}$ It is inexpensive, easily stored at room temperature \& has few systemic side effects. Patient can be ambulatory during induction. Hence patient compliance is better.

\section{METHODS}

The present observational study was conducted in the department of obstetrics \& gynaecology at Bhaskar medical college \& general hospital, Yenkepally from March 2014 to October 2014. 116 pregnant women induced with $25 \mathrm{mcg}$ of vaginal misoprostol were enrolled into the study after their consent. Pregnant women over 34 weeks of gestation with a singleton fetus in cephalic presentation \& a preinduction modified Bishop's score of less than 4 with a reactive non-stress test were included. Exclusion criteria were 'known hypersensitivity' or contraindication to prostaglandins, previous uterine surgery, all malpresentations or abnormal fetal heart rate tracing.

25 mcgm of misoprostol was inserted into the posterior vaginal fornix under aseptic conditions at an interval of four hours till a maximum of four doses. All women underwent non-stress test half an hour prior to insertion of the first dose. Thereafter, fetal monitoring by cardiotocogram, maternal monitoring for cervical changes, onset of labour pains \& blood pressure was done prior to insertion of next dose.

In women with the onset of labour with misoprostol or cervical dilatation of $3 \mathrm{~cm}$, amniotomy and/or oxytocin augmentation was started and further doses of misoprostol were withheld. Demographic profile, gestational age at induction, number of doses of misoprostol, frequency of administration, mode of delivery, induction to delivery interval \& fetomaternal outcome were noted.

Patient was considered to be in active labour if she had 3 uterine contractions in $10 \mathrm{~min}$, each contraction lasting for more than $45 \mathrm{sec}^{3}$

Failure of induction was declared if patient failed to set into labour or if there were no cervical changes even after 4 doses of vaginal misoprostol. ${ }^{5}$

Primary outcome of misoprostol induction was measurement of induction to delivery interval. Secondary outcomes were incidence of operative delivery, indications for operative delivery, uterine hyperstimulation, staining of amniotic fluid with meconium, requirement of oxytocin augmentation \& occurrence of postpartum haemorrhage. Neonatal outcomes recorded were fetal weight, APGAR score at 1 min \& 5 min after birth \& NICU admissions.

\section{RESULTS}

Data was analysed \& tabulated into Tables and Figures (graphs \& pie charts).

Table 1: Distribution of age, parity \& gestational age $(\mathbf{n}=116)$.

\begin{tabular}{|lll|}
\hline Age (years) & $\begin{array}{c}\text { No. of cases } \\
(\mathrm{n=116})\end{array}$ & \\
\hline$<20$ years & 38 & $32.75 \%$ \\
\hline 21-30 years & 78 & $67.24 \%$ \\
\hline$>31$ years & 0 & $0 \%$ \\
\hline Parity & & \\
\hline Primi & 81 & $69.82 \%$ \\
\hline Gravida 2 & 26 & $22.41 \%$ \\
\hline Gravid 3 \& beyond & 9 & $7.76 \%$ \\
\hline Gestational age & & \\
\hline$<34$ weeks & 0 & $0 \%$ \\
\hline $35-36$ weeks & 2 & $1.72 \%$ \\
\hline 37-40 weeks & 55 & $47.42 \%$ \\
\hline$>41$ weeks & 59 & $50.86 \%$ \\
\hline
\end{tabular}

Table 2: Based on modified Bishop score of the cervix $(n=116)$.

\begin{tabular}{|lcl|}
\hline $\begin{array}{l}\text { Preinduction } \\
\text { Bishop score }\end{array}$ & $\begin{array}{l}\text { No. of cases } \\
(\mathbf{n}=116)\end{array}$ & $\%$ \\
\hline$<4$ & 77 & $66.38 \%$ \\
\hline $5-6$ & 34 & $29.31 \%$ \\
\hline $7-10$ & 5 & $4.31 \%$ \\
\hline
\end{tabular}

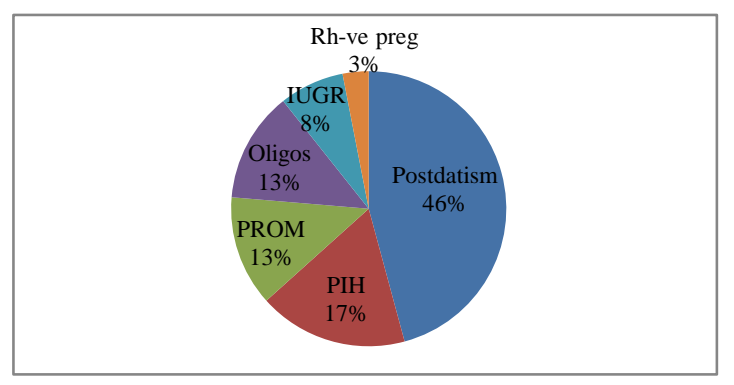

Figure 1: Indications of induction of labour $(n=116)$.

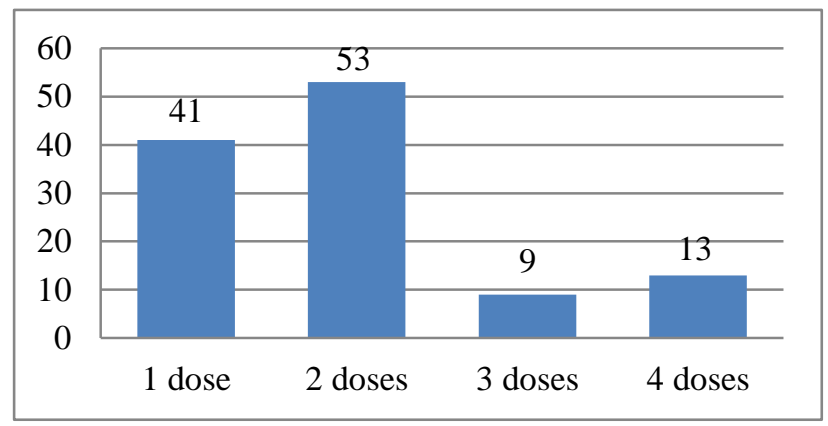

Figure 2: No. of doses of misoprostol for induction $(n=116)$. 
Table 3: Mode of delivery $(n=116)$.

\begin{tabular}{|lll|}
\hline Mode of delivery & $\begin{array}{l}\text { No. of cases } \\
(\mathbf{n = 1 1 6})\end{array}$ & $\begin{array}{l}\text { Percentage } \\
\text { Normal }\end{array}$ \\
\hline Spontaneous & 50 & $51.72 \%$ \\
\hline Forceps & 5 & $83.33 \%$ \\
\hline Vacuum & 5 & $8.33 \%$ \\
\hline LSCS & 56 & $8.33 \%$ \\
\hline For fetal distress & 26 & $48.28 \%$ \\
\hline For PIH & 14 & $46.43 \%$ \\
\hline $\begin{array}{l}\text { For failure to progress } \\
\text { (Occipitopost. \& } \\
\text { midpelvic CPD) }\end{array}$ & 10 & $25 \%$ \\
\hline For PROM & 6 & $17.86 \%$ \\
\hline
\end{tabular}

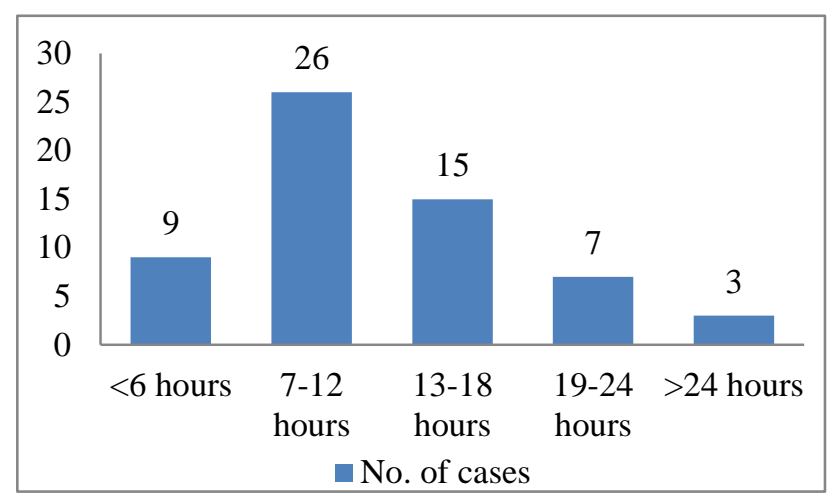

Figure 3: Induction delivery interval in cases of vaginal delivery $(n=60)$.

Table 4: Induction delivery interval based on required No. of doses of misoprostol $(n=60)$.

\begin{tabular}{|c|c|c|c|c|c|}
\hline \multirow{2}{*}{ No. of doses } & \multicolumn{5}{|c|}{$\begin{array}{l}\text { No. of cases with different induction } \\
\text { delivery intervals }\end{array}$} \\
\hline & $\begin{array}{l}<6 \\
\text { hours }\end{array}$ & $\begin{array}{l}7-12 \\
\text { hours }\end{array}$ & $\begin{array}{l}\text { 13-18 } \\
\text { hours }\end{array}$ & $\begin{array}{l}19-24 \\
\text { hours }\end{array}$ & $\begin{array}{l}>24 \\
\text { hours }\end{array}$ \\
\hline Single dose & 9 & 13 & 6 & 1 & 0 \\
\hline 2 doses & 1 & 10 & 9 & 6 & 1 \\
\hline 3 doses & 0 & 0 & 0 & 2 & 0 \\
\hline 4 doses & 0 & 0 & 0 & 0 & 2 \\
\hline
\end{tabular}

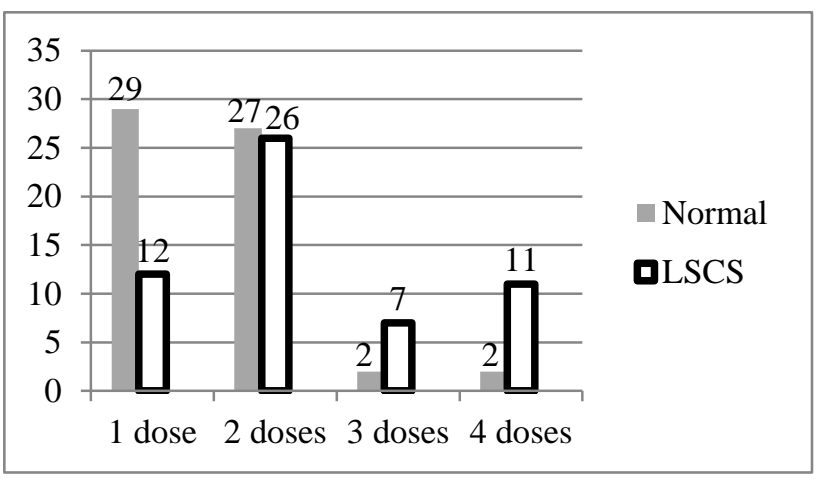

Figure 4: Relation between mode of delivery and No. of doses of misoprostol used $(n=116)$.

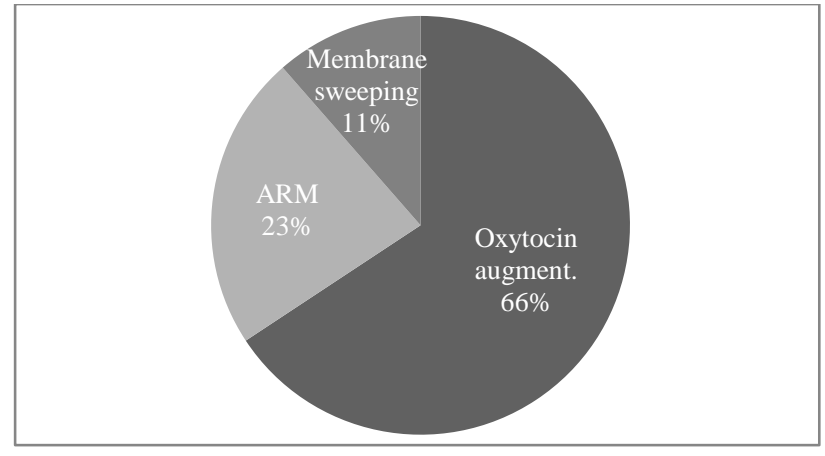

Figure 5: Methods of acceleration of labour in vaginal deliveries $(n=60)$.

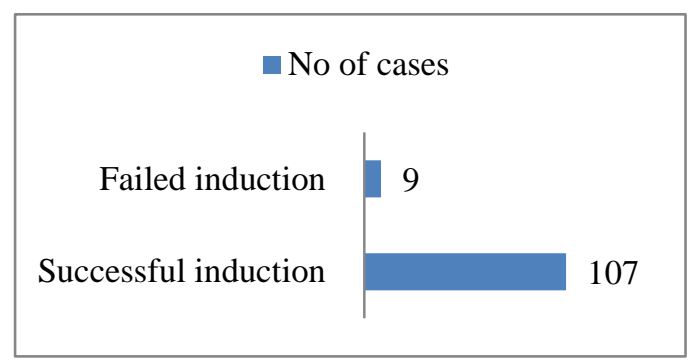

Figure 6: Incidence of Success of induction $(n=116)$.

Table 5: Mode of delivery in cases with successful induction after vaginal misoprostol $(n=107)$.

\begin{tabular}{|lll|}
\hline Mode of delivery & $\begin{array}{l}\text { No. of cases } \\
(\mathbf{n}=\mathbf{1 0 7})\end{array}$ & $\%$ \\
\hline Normal delivery & 60 & 56.075 \\
\hline LSCS & 47 & 43.93 \\
\hline Fetal distress & 23 & 48.94 \\
\hline Uncontrolled PIH and abruptio & 2 & 4.26 \\
\hline Failure to progress due to CPD & 12 & 25.53 \\
\hline PROM $>12$ hours & 10 & 21.28 \\
\hline
\end{tabular}

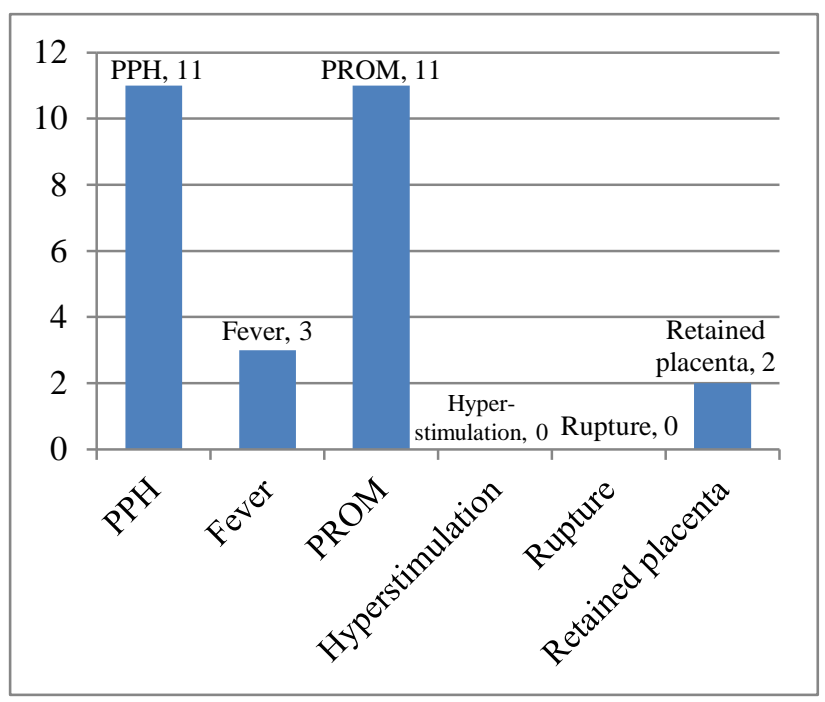

Figure 7: Maternal complications with vaginal misoprostol $(\mathrm{n}=116)$. 
Table 6: Fetal complications with vaginal misoprostol $(n=116)$.

\begin{tabular}{|lll|}
\hline $\begin{array}{l}\text { Fetal outcome } \\
\text { APGAR }\end{array}$ & $\begin{array}{l}\text { No of cases } \\
(\mathbf{n = 1 1 6})\end{array}$ & Percentage \\
\hline$<7 / 5$ & 3 & $2.59 \%$ \\
\hline$>7 / 5$ & 113 & $97.41 \%$ \\
\hline Birth weight & & \\
\hline$<2.5 \mathrm{~kg}$ & 21 & $18.10 \%$ \\
\hline $2.6-3 \mathrm{~kg}$ & 62 & $53.45 \%$ \\
\hline$>3.1 \mathrm{~kg}$ & 33 & $28.45 \%$ \\
\hline NICU admissions & 4 & $3.45 \%$ \\
\hline RDS & 10 & $8.62 \%$ \\
\hline Caput & 2 & $1.72 \%$ \\
\hline Cephalhematoma & 1 & $0.86 \%$ \\
\hline
\end{tabular}

\section{DISCUSSION}

In our study, out of 116 cases recruited for induction with vaginal misoprostol, majority $(67.42 \%)$ of the studied pregnant women were in the age group of 21-30 years \& $69.82 \%$ were primigravidae as seen in Table 1 in accordance with other previous studies which had mean age of $22 \pm 5.2$ years. $^{8}$ Nearly $50.86 \%$ of cases were beyond 41 weeks of gestation \& $47.42 \%$ were term pregnancies (between 37-40 weeks of gestation) as shown in Table 1. Literature shows that prolonged pregnancy $(40 \%)$ is the commonest indication, next common is PIH (13\%) and the third common is PROM $(4 \%) .^{5}$ Our present study also had prolonged pregnancy (46\%), PIH (17\%) \& PROM (13\%) as $1^{\text {st }}$ three common causes of induction as obvious from Table $1 \&$ Figure 1. Out of 116 cases subjected to induction, $66.38 \%$ had preinduction Bishop score of less than 4 as shown in Table 2. Out of 116 cases, 53 required 2 doses of vaginal misoprostol for successful induction as in Figure 2 in correlation with previous studies of $2.26 \pm 0.52$ doses of vaginal misoprostol for successful outcome. ${ }^{5}$

Success of induction was gauged by successful vaginal delivery or change in the cervical Bishop's score from an unfavourable $(<4)$ to favourable $(>4)$ one. As in Figure 6, successful induction was observed in 107 cases out of total of 116. As observed in Table 5, out of 107 successful inductions, 60 had normal vaginal deliveries \& remaining (47) had favourable cervical changes (score of more than 4). Failed induction, seen in 9 cases (Figure 6), had persistent poor bishop score of $<4$ inspite of maximum of 4 doses of vaginal misoprostol in this study.

As in Table 3, out of 116 cases induced with misoprostol, 60 cases $(51.72 \%)$ delivered vaginally successfully after induction \& $56(48.28 \%)$ required lower segment cesarean section for conditions like fetal distress (46.43\%), PIH (25\%), failure to progress $(17.86 \%) \&$ premature rupture of membranes of more than 12 hours $(10.71 \%)$. This is consistent with previous study which showed $14 \%$ fetal distress and 3\% unforeseen CPD as causes for $\mathrm{LSCS}^{5}$ Previous studies show that mean induction-delivery interval is $12.74 \pm 2.60$ hours $^{5}$ and as seen in Figure $3 \&$ Table 4, our study data is also having the induction-delivery interval of 7-12 hours in 26 cases \& 13 to 18 hours in 15 cases. Out of 60 cases of successful vaginal delivery, single dose of vaginal misoprostol was required in 29 cases, 2 doses in 27 cases, 3 doses for 2 cases \& 4 doses for 2 cases as in Table 4 . As in Figure 4, out of 116 cases subjected to vaginal misoprostol, 1 dose of misoprostol resulted in normal delivery in 29 cases \& cesarean delivery in 12 cases while 2 doses of misoprostol resulted in normal vaginal delivery in 27 cases \& cesarean delivery in 26 cases. 3 doses of misoprostol resulted in normal delivery in 2 cases \& cesarean in 7 cases whereas 4 doses of vaginal miso lead to normal delivery in 2 cases \& LSCS in 11 cases. Oxytocin augmentation was quoted to be $11 \%$ in a study. ${ }^{5}$ From Figure 5, we see that oxytocin augmentation is the common mode of labour acceleration $(66 \%)$ in our study also.

As depicted in Figure 7, maternal complications were postpartum haemorrhage in 11 cases, premature rupture of membranes in 11 cases, fever in 3 cases, retained placenta in 2 cases. No case had hyperstimulation \& uterine rupture. From Table 6 we see that fetal complications were also negligible. Good APGAR score of more than 7 was noted in $97.41 \%$ cases. 62 cases (53.45\%) had birth weight of $2.6-3 \mathrm{~kg}$. NICU admissions were in 4 cases $(3.45 \%)$.

Thus, the present study concluded that $25 \mu \mathrm{g}$ vaginal misoprostol is safe for induction of labor. ACOG committee opinion recommends $25 \mu \mathrm{g}$ vaginal misoprostol for cervical ripening and labor induction ${ }^{6}$ as there is lower incidence of tachysystole and hyper stimulation. Our study also showed that use of $25 \mu \mathrm{g}$ vaginal misoprostol every 4 hours did not result in any uterine hyperstimulation or rupture.

Preinduction bishop score of <4 was highly unfavorable for success of labor induction. ${ }^{12}$ Use of $25 \mathrm{mcg}$ of vaginal misoprostol definitely improves the Bishop's score of the cervix \& its response to induction of labour. Various studies showed that in cases of successful induction with vaginal misoprostol, LSCS rate was $19.4 \%$ against $80.6 \%$ cases of vaginal delivery. ${ }^{13,14}$

Even in successful inductions after vaginal misoprostol, higher cesarean rates were seen in induced cases with PROM, PIH and oligohydramnios because fetal hypoxia dominated the decision for early or quick delivery of the fetus by LSCS. Though most LSCS were performed for fetal heart rate abnormalities after misoprostol, there was no increase in the adverse neo-natal outcomes. ${ }^{9,10}$

\section{CONCLUSION}

Labor induction is a medical act of great responsibility which requires an overall assessment of maternal and fetal status. In unfavorable cervices, vaginal misoprostol definitely improves the Bishop score and increases the 
chances of vaginal delivery. Factors like parity, gestational age, unfavorable pre-induction Bishop score, clinical conditions like PIH, PROM and oligohydramnios affect the induction result. $25 \mu \mathrm{g}$ of vaginal Misoprostol inserted once in 4 hours is efficacious for labor induction and safe for mother and fetus. In a low resource setting, it is a good alternative to other methods of induction.

Funding: No funding sources

Conflict of interest: None declared

Ethical approval: The study was approved by the institutional ethics committee

\section{REFERENCES}

1. Mackenzie IZ. Induction of labor at the start of new millennium. Reproduction. 2006;131(60):989-98.

2. ACOG. Induction of labor. In: ACOG, eds. ACOG Practice Bulletin Number 10. Washington DC, USA: American College of Obstetricians and Gynecologists; 1999.

3. Sareen Sweta, Chawla Indu, Singh Pushpa. Labour induction with $50 \mu \mathrm{g}$ of vaginal misoprostol: can we reduce induction delivery interval safely? J Obstet Gynaecol India. 2014 Aug;64(4):270-3.

4. St. Onge RD, Connera GT. Preinduction cervical ripening, a comparison of intra-cervical $\mathrm{PGE}_{2}$ gel vs. the Foley's catheter. Am J Obstet Gynaecol. 1995; 172;687-90.

5. Deshmukh Varsha, Lakshmikanth, Yelikar Kanan Avinash, Waso Vandana. Comparative study of efficacy and safety of oral versus vaginal misoprostol for induction of labor. J Obstet Gynaecol India. 2013 Sep-Oct;63(5):321-4.

6. ACOG. Induction of labor with misoprostol. In: ACOG, eds. ACOG Committee Opinion No. 228.
Washington DC 7: American College of Obstetricians and Gynecologists; 1999.

7. Nasreen Abbasi, Nargis Danish, Farah Shakoor, Zaheda Parveen, Syed Ahmed Bilal. Effectiveness and safety of vaginal misoprostol for induction of labour in unfavourable cervix in 3 rd trimester. $\mathrm{J}$ Ayub Med Coll Abbottabad. 2008;20(3):33-5.

8. Sanchez Ramos L, Peterson D, Delke I. Induction with $\mathrm{PGE}_{1}$, misoprostol compared with dinoprostone vaginal insert: randomized trial. Obstet Gynecol. 1998;91:401-5.

9. Wing DA, Rahall A, Jones MM, Goodwin TM, Paul RH. Misoprostol: an effective agent for cervical ripening and labor induction. Am J Obstet Gynaecol. 1995;172:1811-6.

10. Mindle WR, Young DC. Vaginal misoprostol for induction of labor; randomized control trial. Obstet Gynaecol. 1996;88:521-5.

11. Crane JM. Factors predicting labor induction success: a critical analysis. Clin Obstet Gynaecol. 2006;49:573-84.

12. Giugliano E, Cagnazzo E, Milillo V, Moscarini M, Vesce F, Caserta D, et al. The risk factors for failure of labor induction: a cohort study. J Obstet Gynaecol India. 2014 Apr;64(2):111-5.

13. Kelly AJ, Malik S, Smith L. Vaginal $\mathrm{PGE}_{2}$ and $\mathrm{PGF}_{2 \alpha}$ for induction of labor at term. Cochrane Database Syst Rev. 2009;7:CDOD3101.

DOI: $10.5455 / 2320-1770 . i j r \operatorname{cog} 20150436$

Cite this article as: Kothapally KR, Kavati V, Bongu V. Study of induction of labour with vaginal misoprostol in a tertiary hospital in a rural area of Telangana, India. Int J Reprod Contracept Obstet Gynecol 2015;4:465-9. 